\title{
Twelve complete chloroplast genomes of wild peanuts: great genetic resources and a better understanding of Arachis phylogeny
}

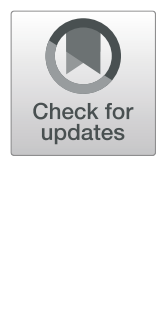

Juan Wang ${ }^{1{ }^{* \dagger}}$, Yuan $\mathrm{Li}^{2+}$, Chunjuan $\mathrm{Li}^{1}$, Caixia Yan ${ }^{1}$, Xiaobo Zhao ${ }^{1}$, Cuiling Yuan ${ }^{1}$, Quanxi Sun ${ }^{1}$, Chengren Shi ${ }^{1}$ and Shihua Shan ${ }^{1 *}$

\begin{abstract}
Background: The cultivated peanut (Arachis hypogaea) is one of the most important oilseed crops worldwide, however, its improvement is restricted by its narrow genetic base. The highly variable wild peanut species, especially within Sect. Arachis, may serve as a rich genetic source of favorable alleles to peanut improvement; Sect. Arachis is the biggest taxonomic section within genus Arachis and its members also include the cultivated peanut. In order to make good use of these wild resources, the genetic bases and the relationships of the Arachis species need first to be better understood.

Results: Here, in this study, we have sequenced and/or assembled twelve Arachis complete chloroplast (cp) genomes (eleven from Sect. Arachis). These cp genome sequences enriched the published Arachis cp genome data. From the twelve acquired cp genomes, substantial genetic variation (1368 SNDs, 311 indels) has been identified, which, together with 69 SSR loci that have been identified from the same data set, will provide powerful tools for future explorations. Phylogenetic analyses in our study have grouped the Sect. Arachis species into two major lineages (I \& II), this result together with reports from many earlier studies show that lineage II is dominated by AA genome species that are mostly perennial, while lineage I includes species that have more diverse genome types and are mostly annual/biennial. Moreover, the cultivated peanuts and A. monticola that are the only tetraploid (AABB) species within Arachis are nested within the AA genome species-dominated lineage, this result together with the maternal inheritance of chloroplast indicate a maternal origin of the two tetraploid species from an AA genome species.
\end{abstract}

Conclusion: In summary, we have acquired sequences of twelve complete Arachis cp genomes, which have not only helped us better understand how the cultivated peanut and its close wild relatives are related, but also provided us with rich genetic resources that may hold great potentials for future peanut breeding.

Keywords: Arachis, Peanut, Chloroplast genome, Phylogeny, SNDs, SSRs, Genome type, Genetic variation

\section{Background}

The genus Arachis L. has gained significant research interest due to one of its member species, the cultivated peanut (A. hypogaea L.) that is an economically important oilseed crop worldwide [1, 2]. Arachis species are endemic to South America, and it is from there the cultivated peanut has been spread out and planted in many different parts of the world that are far from its cradleland, among which China represents the largest producer today [1-3].

\footnotetext{
*Correspondence: wangjuan_1984@163.com; shansh_spri@163.com

†Juan Wang and Yuan Li contributed equally to this work.

'Shandong Peanut Research Institute, Qingdao, China

Full list of author information is available at the end of the article
}

Morphologically, two subspecies have been identified within A. hypogaea, which can be further sorted into six botanical varieties [4]. Although phenotypically variable, A. hypogaea has a relatively low level of genetic variation comparing to its wild relatives [5-10], which may be due to domestication, and a possibly recent and single polyploidization origin as well as the ploidy difference between the cultivated and wild peanut $[1,2,11,12]$. The limited genetic variation of $A$. hypogaea restrains the further improvement of this crop, especially from the perspective of resistance to diseases and pests $[1,2]$. Luckily, interspecific hybridization between the Arachis species is possible especially with the help of modern technology and there is a

C The Author(s). 2019 Open Access This article is distributed under the terms of the Creative Commons Attribution 4.0 International License (http://creativecommons.org/licenses/by/4.0/), which permits unrestricted use, distribution, and 
rich source of genetic variation among the closely related wild relatives within the Arachis genus that may be very useful for broadening the genetic basis of the cultivated peanut $[2,4,12-15]$.

So far, over 80 species have been identified within the Arachis genus [2], which were arranged into nine taxonomic sections (including Sect. Arachis, Sect. Erectoides and Sect. Procumbentes) by Krapovickas and Gregory [16]; the cultivated peanut belongs to Sect. Arachis. Many useful resistances to a number of diseases (e.g. early leaf spot, late leaf spot, peanut rust and rosette disease) and pests (such as nematodes, armyworm and corn earworm) that can cause serious yield loss in the cultivated peanut have been identified from the wild Sect. Arachis species [2]. For example, accessions of $A$. duranensis Krapov. \& W.C. Gregory and A. cardenasii Krapov. \& W.C. Gregory that belong to Sect. Arachis have been found to be resistant to twelve or more different diseases/pests, representing two of the richest sources of novel resistant alleles for cultivated peanut $[2,17]$. To more efficiently make use of these rich genetic resources for peanut breeding, a better understanding of the genomes and phylogenetic relationships of the species within Arachis is a prerequisite.

As mentioned above, there are nine taxonomic sections within the genus Arachis that are arranged based on morphology, crossability, cytogenetics, hybrid viability and geographic distribution $[2,4,16,18,19]$, however, this grouping has been challenged by molecular phylogenetic studies [20, 21]. Among the nine Arachis sections, Sect. Arachis that includes the cultivated peanut is the largest, the most diverse and the most derived one: it includes more than one third of the Arachis species, and harbors both annual and perennial species that may also differ in chromosome number, ploidy level and genome type $[1,4]$. Many attempts to infer the phylogenetic relationship among Arachis species have been made, though incongruence between markers and studies is very common $[8,10$, $11,14,20,22-26]$. The rapidly developing high-throughput sequencing technology may provide us with a good chance to make use of the chloroplast (cp) genome data for helping improve the situation [27], due to several advantages of the cp genome data in phylogenetic analyses. First, cp genome data harbors many different gene loci and non-coding regions that contain relatively large amount of DNA sequence information, this would not only boost the resolving power of phylogenetic inference, but also dramatically reduce stochastic errors that are associated with limited sequence information of single genes in traditional phylogeny construction [28, 29]. Second, as being maternally inherited, cp genome in Arachis may provide the best tool for inferring the maternal origin of the cultivated peanut. Third, the haploid nature of the cp genome severely restrains the occurrence of non-homologous recombination events, which will make cp genome suffer less from recombination in phylogenetic analysis [30, 31]. Finally, the cp genome has a relatively small size compared to nuclear genome, which means that it's relatively cheap and easy to sequence and analyze [27].

Apart from the advantages in phylogenetic analysis as mentioned above, the cp genome is also useful for developing DNA barcodes that can be helpful, for example, in distinguishing taxa, as well as for cp genetic engineering that transfers foreign genes into cp genomes [27]. Comparing to nuclear transgenic plants, chloroplast genetic engineering has several advantages, including a high level of transgene expression and no escape of transgenes through pollen [27]. Now there are already plenty of successful cases of $\mathrm{cp}$ genetic engineering that have been performed [27]. Moreover, cp genes have also been found to possibly contribute to host plants' resistance to environmental stresses [32, 33]. Although the cp genome is very useful, there are, however, still a very limited number of $\mathrm{cp}$ genomes available for the Arachis species so far. The first two Arachis complete cp genomes that have been sequenced are from the cultivated peanut, A. hypogeae, and were reported rather recently by Schwarz et al. [34] and Prabhudas et al. [35]. After that, Yin et al. [21] acquired the complete cp genome sequences from seven different Arachis species including the domesticated peanut, while Wang et al. [36] explored the complete cp genome sequences of four $A$. hypogeae botanical varieties. To sum it up, there are only thirteen Arachis complelete $\mathrm{cp}$ genomes from seven different species that have been sequenced so far.

In this study, we have assembled a total of twelve complete cp genomes of Arachis species, among which eleven are from Sect. Arachis while the last one is from Sect. Erectoides, and these data represent a rich source of genetic variation that may hold great potential for peanut improvement. These sequences together with earlier published Arachis cp genome data have helped us better understand the Arachis cp genomes and the phylogenetic relationships among species within and among Arachis sections, as well as give more information about the wild maternal origin of the cultivated peanut.

\section{Results}

Basic characteristics of the acquired Arachis chloroplast genomes

A total of twelve Arachis species that belong to Sect. Arachis (A. monticola Krapov. \& Rigoni [GRIN accession number: PI-219824], A. duranensis [PI-263133], A. stenosperma Krapov. \& W.C. Gregory [PI-338280], A. batizocoi Krapov. \& W.C. Gregory [PI-298639], A. cardenasii [PI262141], A. helodes Martius ex Krapov. \& Rigoni [Collector no.: Manso 588], A. correntina (Burkart) Krapov. \& W.C. Gregory [PI-331192], A. hoehnei Krapov. \& W.C. Gregory [Collector no.: KG30006], A. chacoensis Krapov. \& W.C. Gregory (now known as A. diogoi Hoehne) [PI-276235] 
and A. villosa Benth. [PI-210555], A. ipaënsis Krapov. \& W.C. Gregory [37]) and Sect. Erectoides (A. paraguariensis ssp. paraguariensis Chodat \& Hassl. [PI-331187]) have their cp genomes sequenced and/or assembled in the present study (Table 1). In comparison to nuclear genome, cp genomes of land plants have highly-conserved circular DNA molecules with two inverted repeat (IR) regions (IRa and IRb) (identical but in opposite orientations) that were separated by small (SSC) and large (LSC) single copy (SC) regions [38]. The twelve cp genomes assembled within this study had this typical quadripartite structure (Figs. 1 and 2), and with total lengths varying from 156,287 bp (A. stenosperma) to $156,491 \mathrm{bp}$ (A. cardenasii) (Additional file 1), which were similar to those earlier published Arachis cp genomes [21, 34-36]. The four different genome regions ranged in size from $85,830 \mathrm{bp}$ (A. duranensis) to $85,980 \mathrm{bp}$ (A. villosa) for LSC, from $18,796 \mathrm{bp}$ (A. correntina and A. monticola) to $18,942 \mathrm{bp}$ (A. cardenasii) for SSC and from 25,776 bp (A. ipaënsis) to 25,842 bp (A. batizocoi) for IRa/b (Additional file 1).

As with earlier reports about Arachis cp genomes [21, 34-36], a total of 110 unique genes were found in each of the twelve assembled $\mathrm{cp}$ genomes, including four ribosomal RNA (rRNA) genes, 76 protein-coding genes and 30 transfer RNA (tRNA) genes (Additional files 1 and 2). The gene order of these 110 genes was the same for all the twelve assembled cp genomes (Fig. 1), and was also in line with all published Arachis cp genomes so far [21, 34-36]. In addition, six of the identified tRNA genes, and eleven of the protein-coding genes contained introns (Additional file 2).

Similar to earlier studies [34, 35], the overall GC contents of the twelve assembled cp genomes were 36.3$36.4 \%$ and the GC contents were not evenly distributed among the different genome regions: IRs (42.9-43.0\%) had higher GC content than LSC (33.8\%) and SSC (29.9$30.3 \%$ ) (Additional file 1). The high GC content of IRs was mostly due to a gene region (including the $r r n 23$, trnAUGC and trnl-GAU genes) that stands out in its GC content comparing to the rest of the cp genome (Fig. 2).

\section{Genetic variation and SSRs}

Among the twelve cp genomes that were assembled in the present study, a total of 1368 single nucleotide divergences (SNDs) $(0.87 \%)$ were identified, and most of these SNDs were distributed within the LSC region (959, constituting $1.11 \%$ of the LSC sequence), but the SSC region contained the highest proportion of SNDs (299, 1.58\%), while the SND content of the IRa/b regions was the lowest (55 each, 0.21\%) (Table 2, Fig. 2 ). The cp genome region with the highest density of SNDs was located at the intergenic spacer between the $p s b \mathrm{E}$ and $p e t \mathrm{~L}$ genes within LSC, where 47 SNDs were found within $500 \mathrm{bp}$ (Table 3).
There were totally 311 insertions/deletions (indels) $(0.20 \%)$ that had been found within the twelve cp genomes, and $>90 \%$ of which were short indels (1-10 bp) (Table 2). The distribution of these indels among the four cp genome regions was very similar to that of SNDs: LSC had the largest number (241, 0.27\%), but SSC held the highest density $(64,0.34 \%)$, while the IR regions was the lowest in both number and density (6 per region, $0.02 \%$ ) (Table 2, Fig. 2). The cp genome regions with the highest density of indels were found at two $500 \mathrm{bp}$-long sequence blocks: one included the intergenic spacer between the trnQ-UUG and $a c c \mathrm{D}$ genes within LSC, while the other was within SSC and was composed of the intergenic spacer between the rpl32 and trnL-UAG genes, the trnLUAG gene as well as the intergenic spacer between the trnL-UAG and ccsA genes. Within both regions, eleven indels were detected, respectively (Table 4). The result of the VISTA analysis is consistent with the results of SNDs and indels: almost the entire IR regions were conserved, while the identified conserved regions within SCs were short and scattered (Table 4).

Although the IR regions were rather conserved, the IR boundaries could vary greatly even within species [39], so in order to detect any possible IR border polymorphism, we compared the four IR-SC borders among the twelve assembled genomes, but no difference was found at the IRa-SSC border, while at the LSC-IRa, SSC-IRb and IRb-LSC borders, only small differences were discovered from A. ipaënsis, A. cardenasii and A. helodes (Fig. 3). The rps19 gene at the IRa-LSC boundary expanded $9 \mathrm{bp}$ from the LSC region to the IRa side in $A$. cardenasii while it stops at the LSCIRa junction in the rest of the species (Fig. 3). The length of the $y c f 1$ gene (in SSC) at the SSC-IRb boundary was 4805 bp for A. ipaënsis/A. helodes and $4778 \mathrm{bp}$ for A. cardenasii, which were shorter than those in the other species that were all $4811 \mathrm{bp}$ (Fig. 3). On one side of the IRb-LSC boundary, the spacer between the $r p l 2$ gene (in IRb) and the IRb-LSC junction was $69 \mathrm{bp}$ long for $A$. cardenasii while this spacer for the rest of the species had a length of $60 \mathrm{bp}$. On the other side of the IRb-LSC boundary, the lengths of the spacers between the IRb-LSC junction and the $\operatorname{trn} \mathrm{H}-\mathrm{GUG}$ gene (in LSC) were, respectively, $61 \mathrm{bp}$ and $71 \mathrm{bp}$ for $A$. cardenasii and A. helodes while those of the rest species were all 64 bp (Fig. 3).

With MISA analysis, 69 universal SSR loci were detected within the twelve assembled cp genomes, among which 59 were mononucleotide, nine were dinucleotide and one was tetranucleotide. The majority of the identified SSRs were composed of A or T, which was consistent with earlier observations about cp SSRs in other taxa $[40,41] .41$ of the identified SSR loci showed variation among the twelve acquired Arachis cp genomes, and most of them (75.6\%) were located in the LSC region, followed by SSC (24.4\%), and none was found within IR 
Table 1 The Arachis species that have been analyzed in the present study

\begin{tabular}{lll}
\hline Species & $\begin{array}{l}\text { Genome } \\
\text { type }\end{array}$ & $\begin{array}{l}\text { Life History } \\
\text { Strategy }\end{array}$ \\
\hline
\end{tabular}

Sect. Arachis

Domesticated peanut varieties

A. hypogaea AABB Annual/ 4x Shandong Peanut var. hypogaea biennial Research Institute,

Shandong Academy of Agricultural

Sciences, Qingdao,

China (SPRI-SAAS)

$\begin{array}{lllll}\begin{array}{l}\text { A. hypogaea } \\ \text { var. hirsuta }\end{array} & \text { AABB } & \begin{array}{l}\text { Annual/ } \\ \text { biennial }\end{array} & 4 x & \text { SPRI-SAAS } \\ \begin{array}{l}\text { A. hypogaea } \\ \text { var. fastigiata }\end{array} & \text { AABB } & \begin{array}{l}\text { Annual/ } \\ \text { biennial }\end{array} & 4 x & \text { SPRI-SAAS } \\ \begin{array}{l}\text { A. hypogaea } \\ \text { var. vulgaris }\end{array} & \text { AABB } & \begin{array}{l}\text { Annual/ } \\ \text { biennial }\end{array} & 4 x & \text { SPRI-SAAS }\end{array}$

Wild allotetraploid species

A. monticola AABB Annual/ 4x Nanning Branch biennial of National Field Genbank for Arachis species, Guangxi Academy of Agricultural Sciences, Nanning, China (NB-NFGAS- GAAS)

Wild diploid species

\begin{tabular}{|c|c|c|c|c|}
\hline A. batizocoi & KK & $\begin{array}{l}\text { Annual/ } \\
\text { biennial }\end{array}$ & $2 x$ & NB-NFGAS- GAAS \\
\hline A. cardenasii & $\mathrm{AA}$ & Perennial & $2 x$ & NB-NFGAS- GAAS \\
\hline $\begin{array}{l}\text { A. chacoensis/ } \\
\text { A. diogoi }\end{array}$ & $\mathrm{AA}$ & Perennial & $2 x$ & NB-NFGAS- GAAS \\
\hline A. correntina & AA & Perennial & $2 x$ & NB-NFGAS- GAAS \\
\hline A. duranensis & $\mathrm{AA}$ & $\begin{array}{l}\text { Annual/ } \\
\text { biennial }\end{array}$ & $2 x$ & NB-NFGAS- GAAS \\
\hline A. helodes & $\mathrm{AA}$ & Perennial & $2 x$ & NB-NFGAS- GAAS \\
\hline A. hoehnei & $\mathrm{AA}$ & $\begin{array}{l}\text { Annual/ } \\
\text { biennial }\end{array}$ & $2 x$ & NB-NFGAS- GAAS \\
\hline $\begin{array}{l}\text { A. } \\
\text { stenosperma }\end{array}$ & $\mathrm{AA}$ & $\begin{array}{l}\text { Annual/ } \\
\text { biennial }\end{array}$ & $2 x$ & NB-NFGAS- GAAS \\
\hline A. villosa & $\mathrm{AA}$ & Perennial & $2 x$ & NB-NFGAS- GAAS \\
\hline A. ipaënsis & $\mathrm{BB}$ & $\begin{array}{l}\text { Annual/ } \\
\text { biennial }\end{array}$ & $2 x$ & * \\
\hline
\end{tabular}

Sect. Erectoides

A. EE Perennial 2x NB-NFGAS-GAAS
paraguariensis

* The cp genome sequence data for A. ipaënsis were downloaded from the NCBI SRA database

(Additional file 3). PCR primers have been designed for each of the 41 variable SSR loci (Additional file 3).

\section{Phylogeny of the studied Arachis species}

Two different phylogenetic methods (Maximum Likelihood and Bayesian Inference) were used to infer the phylogenetic relationships between the analyzed species, and both methods generated nearly identical trees, we therefore only showed the Bayesian Inference phylogenetic tree (Fig. 4) (the Maximum Likelihood trees are available on request). Considering the much slower substitution rate of the IR regions that may not be suitable for inferring the relationship between closely related Sect. Arachis species, we therefore constructed phylogeny both with and without them. In addition, phylogenetic analyses of species differing in ploidy levels might produce unusual results comparing to those only involving species with the same ploidy level $[1,20]$, we thus tried to exclude the two tetraploid species (A. hypogeae and A. monticola) and only used the diploid species to infer phylogenetic trees with whole genome data. Furthermore, indels were not considered in the abovementioned phylogenetic analyses, however, information embedded within indels might help improve the resolution of phylogeny for closely related species [42]. We therefore performed Bayesian inferences of phylogeny that took indel information from the entire cp genome into consideration. However, among all the different situations we considered, the arrangement of major lineages and sublineages in the acquired phylogenetic trees always remained consistent (Figs. 4, 5, 6 and 7). Below, we would only present the results from the Bayesian Inference tree that was based on the whole cp genome data (excluding the indel information).

A total of 16 Arachis genomes (the twelve genomes assembled in this study plus four earlier published $A$. hypogaea genomes) had been included in this part of the phylogenetic analyses, and they fell into two wellsupported major lineages (I, II) in the inferred phylogenetic trees (Bootstrap [BS] value: 100; Bayesian posterior probability [BPP]: 1.0) (Fig. 4). Lineage I was composed of one $\mathrm{BB}$ genome species (A. ipaënsis) and two AA genome species (A. cardenasii and $A$. helodes), while lineage II comprised the rest of the species (AA genome species: A. duranensis, A. hoehnei, A. chacoensis, A. villosa, A. stenosperma, and $A$. correntina; AABB genome species: four $A$. hypogaea varieties and $A$. monticola; KK genome species: A. batizocoi; EE genome species: A. paraguariensis) (Fig. 4). Our molecular dating analysis implied that these two major lineages split 0.818 million years ago (Mya) (Fig. 8), and this divergence time was slightly shorter than the divergence time that was estimated between $A$. duranensis (in the present study belonging to lineage II) and A. ipaënsis (in the present study belonging to lineage I) (2.16 Mya) by Bertioli et al. [43], which was perhaps not surprising considering the latter was based on data from the bi-parentally inherited nuclear genome while the present study used cp genome (uniparentally inherited) data. Both lineages didn't differ much in their GC contents: $35.13 \%$ for lineage I while $35.09 \%$ for lineage II. 


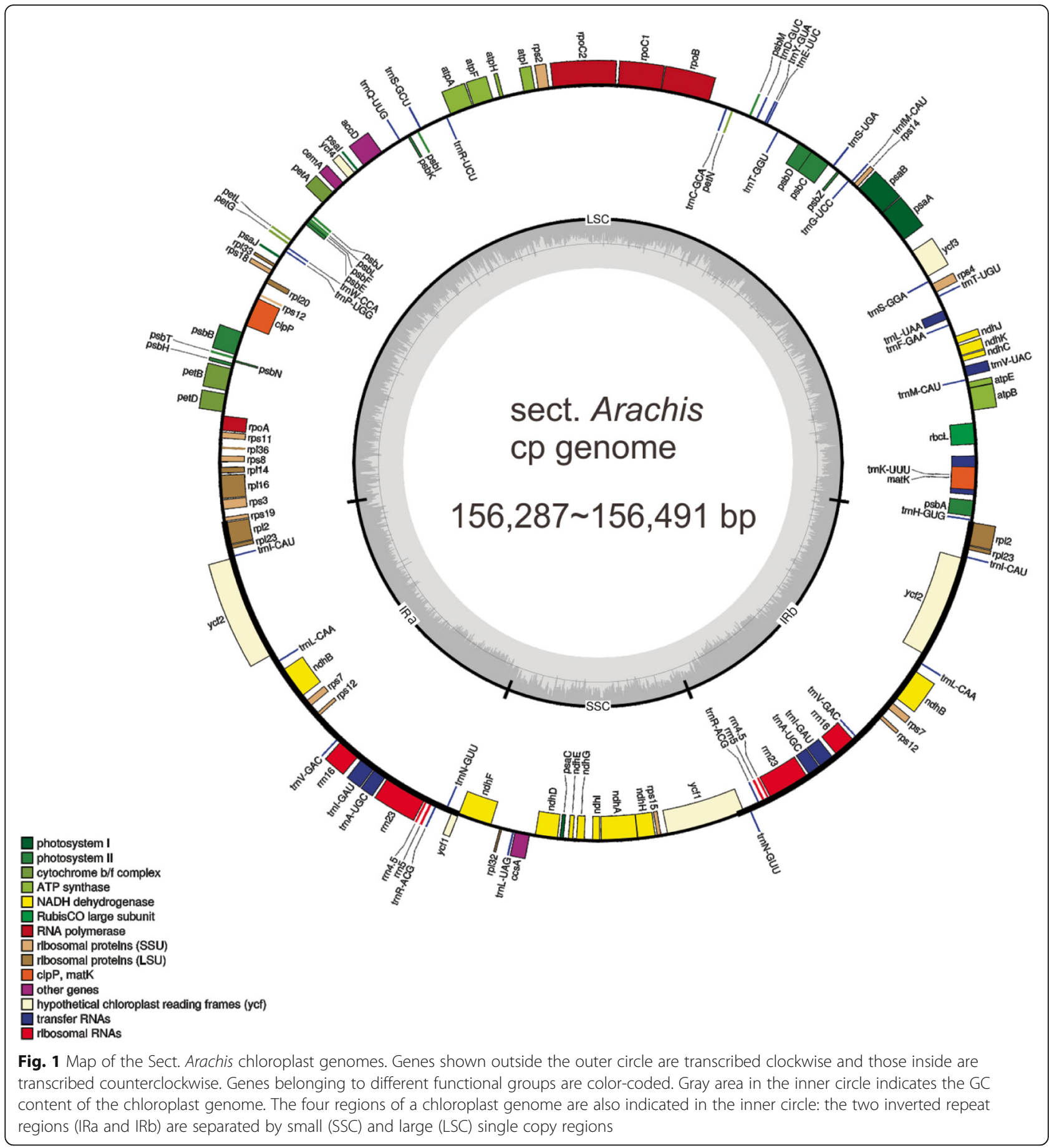

Within lineage I, the two AA genome species (A. cardenasii and $A$. helodes) grouped closely together (BS: 100; BPP: 1.0 ), and their most recent common ancestor was dated back to $0.3086 \mathrm{Mya}$ (Figs. 4 and 8). In contrast, the split time between these two AA species and the $\mathrm{BB}$ genome species (A. ipaënsis) was much earlier: 0.6718 Mya (Fig. 8).

The time to the most recent common ancestor of lineage II was 0.2917 , and the species within this lineage diverged rapidly (Fig. 8). Within lineage II, two distinct sublineages can be recognized: the first sublineage (BS: 100; BPP: 1.0) was composed of two AABB genome species (A. hypogaea and A. monticola) plus one AA genome species (A. chacoensis), and the most recent common ancestor of this sublineage was dated back to 0.1412 Mya (Figs. 4 and 8). Within this first sublineage, the two AABB genome species (the cultivated peanut and A. monticola) formed a highly supported clade (BS: 100; BPP: 1.0), the estimated time to the most recent common ancestor of 


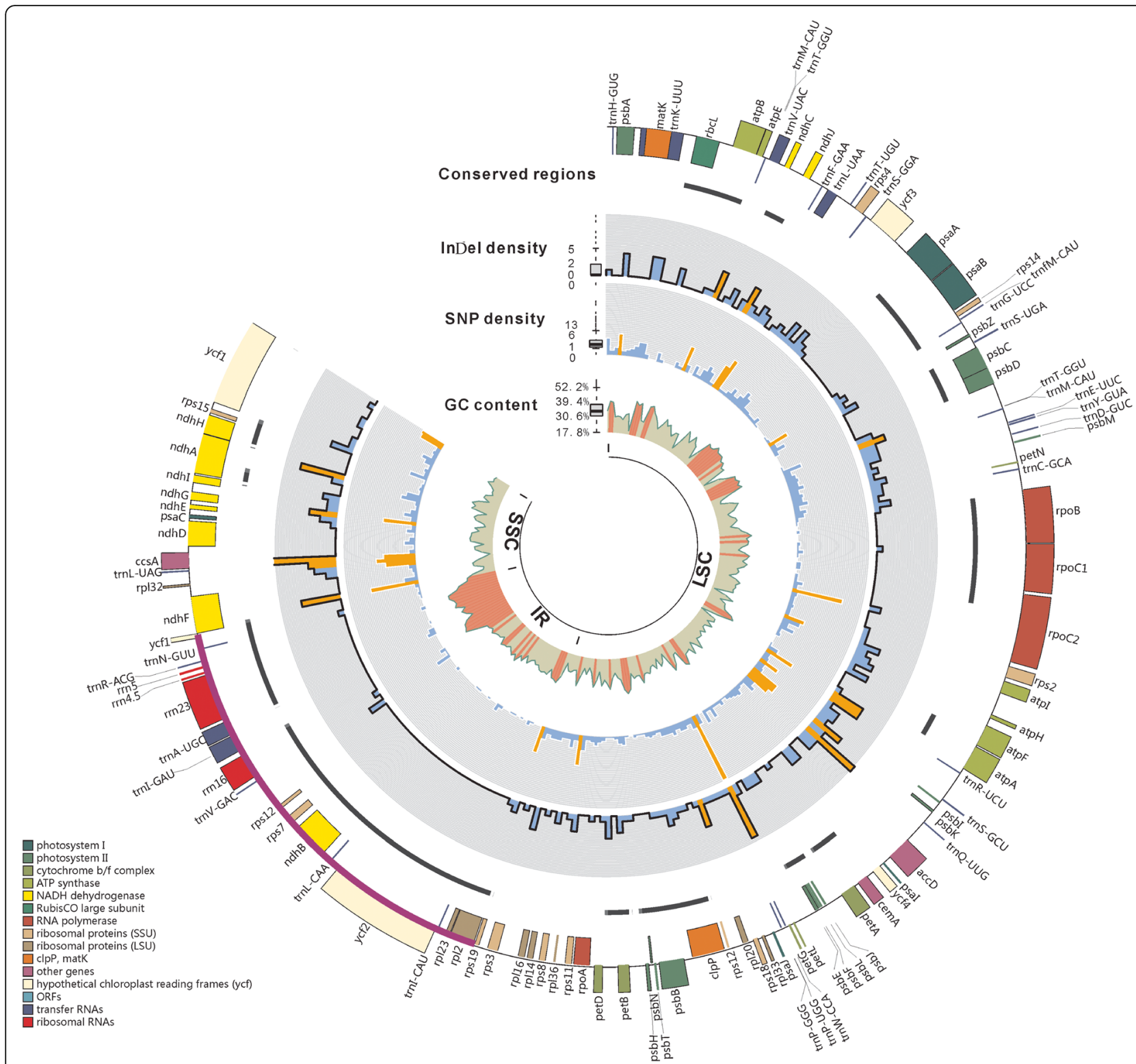

Fig. 2 Circos plot showing basic characteristics of the twelve Arachis cp genomes acquired in this study. The GC content, the SND density, the indel density, and the conserved regions are shown from the inner to outer rings. The outermost rectangles are $\mathrm{cp}$ genes belonging to different functional groups that are color-coded. The high-density areas are highlighted in orange for GC content (> 53.06\%), SNDs (> 8.39\%) and indels (> 5.34\%). Boxplots for the GC contents, the SND and indel densities have also been shown, with bars representing the median, the bottom and top of the boxes representing, respectively, the 25 and $75 \%$ percentiles, and whiskers extending out to 1.5 times the interquartile range. Dots are outliers

Table 2 A summary of the SNDs and indels identified among the twelve acquired chloroplast genomes

\begin{tabular}{|c|c|c|c|c|c|}
\hline \multirow[b]{2}{*}{ Region } & \multirow[b]{2}{*}{ Length } & \multicolumn{2}{|l|}{ SNDs } & \multicolumn{2}{|l|}{ indels } \\
\hline & & Number & Proportion (\%) & Number & Proportion (\%) \\
\hline LSC & 86.197 & 959 & $1.11 \%$ & 241 & $0.27 \%$ \\
\hline SSC & 18,876 & 299 & $1.58 \%$ & 64 & $0.34 \%$ \\
\hline $\mathbb{R}$ & 25,825 & 55 & $0.21 \%$ & 6 & $0.02 \%$ \\
\hline Complete genome & 156,718 & 1368 & $0.87 \%$ & 311 & $0.20 \%$ \\
\hline
\end{tabular}


Table 3 The genome areas identified to be rich in SNDs among the twelve acquired chloroplast genomes. Genome areas that have more than 10 SNDs per 500 bp are considered to be rich in SNDs

\begin{tabular}{|c|c|c|c|c|}
\hline Genome position & Count & Region & Genomic context & Sequence content \\
\hline $66,000-66,500$ & 47 & LSC & psbE $\sim p e t \mathrm{~L}$ & spacer \\
\hline $44,500-45,000$ & 34 & LSC & rpoc2 & coding \\
\hline $112,000-112,500$ & 32 & IRA; SSC & $\operatorname{trnN-GUU\sim ndhF;ndhF~}$ & spacer; coding \\
\hline $115,000-115,500$ & 26 & SSC & rp/32; rp/32 trnL-UAG & coding; spacer \\
\hline $15,000-15,500$ & 23 & LSC & 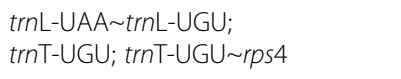 & spacer; coding; spacer \\
\hline $119,500-120,000$ & 22 & SSC & $p s a C \sim n d h \mathrm{E} ; n d h \mathrm{E} \sim n d h \mathrm{G}$ & spacer; spacer \\
\hline $115,500-116,000$ & 21 & SSC & $\begin{array}{l}\text { rp/32 trnL-UAG; trnL-UAG; } \\
\text { trnL-UAG cCSA }\end{array}$ & spacer; coding; spacer \\
\hline $53,000-53,500$ & 20 & LSC & $\operatorname{trnR}-\mathrm{UCU}$; trnR-UCU trnS-GCU & coding; spacer \\
\hline $56,000-56,500$ & 20 & LSC & psbK; psbK trnQ-UUG & coding; spacer \\
\hline $56,500-57,000$ & 20 & LSC & $\begin{array}{l}\text { psbK trnQ-UUG; trnQ-UUG; } \\
\text { trnQ-UUG accD }\end{array}$ & spacer; coding; spacer \\
\hline $81,000-81,500$ & 20 & LSC & rps11 rp/36; rp/36; rp/36 rps8 & spacer; coding; spacer \\
\hline $114,500-115,000$ & 20 & SSC & $n d h F \sim r p / 32 ; r p / 32$ & spacer; coding \\
\hline $86,000-86,500$ & 18 & LSC;IRA & rps19; rps19 rp/2; rp/2 & coding; spacer; coding \\
\hline $10,000-10,500$ & 17 & LSC & $\operatorname{trnV} \mathrm{U} \cup \mathrm{AC}$; $\operatorname{trnV-UAC\sim ndhC}$ & coding; spacer \\
\hline $14,500-15,000$ & 17 & LSC & $\operatorname{trnL-UAA\sim trnL-UGU}$ & spacer \\
\hline $57,000-57,500$ & 17 & LSC & $\operatorname{trnQ}-\cup \cup G \sim a c c D$ & spacer \\
\hline $130,500-130,894$ & 17 & SSC & ycf1 & coding \\
\hline $130,000-130,500$ & 16 & SSC & $y c f 2$ & coding \\
\hline $1500-2000$ & 14 & LSC & psbA trnK-UUU; trnK-UUU & spacer; coding \\
\hline $25,000-25,500$ & 14 & LSC & $\operatorname{trnG-UCC\sim psbZ}$ & spacer \\
\hline $48,000-48,500$ & 14 & LSC & atpl atpH & spacer \\
\hline $54,500-55,000$ & 14 & LSC & $\operatorname{trnR}-\mathrm{UCU} \sim \operatorname{trn} \mathrm{S}-\mathrm{GCU}$ & spacer \\
\hline $29,000-29,500$ & 13 & LSC & psbD; psbD trnT-GGU & coding; spacer \\
\hline $29,000-29,500$ & 13 & LSC & psbD; psbD trnT-GGU & coding; spacer \\
\hline $122,500-123,000$ & 13 & SSC & $n d h A$ & coding \\
\hline $18,500-19,000$ & 12 & LSC & $y c f 3 ; y c f 3 \sim p s a A$ & coding; spacer \\
\hline $48,500-49,000$ & 12 & LSC & atpl atpH & spacer \\
\hline $125,500-126,000$ & 12 & SSC & rps15; rps15 ycf1 & coding; spacer \\
\hline $0-500$ & 11 & LSC & $\operatorname{trnH}-\mathrm{GUG} ; \operatorname{trnH}-\mathrm{GUG} \sim p s b \mathrm{~A} ; p s b \mathrm{~A}$ & coding; spacer; coding \\
\hline $13,000-13,500$ & 11 & LSC & $\begin{array}{l}\text { ndhJ } \operatorname{trnF} \text {-GAA; trnF-GAA; } \\
\text { trnF-GAA trnL-UAA }\end{array}$ & spacer; coding; spacer \\
\hline $4000-4500$ & 10 & LSC & matK rbcL & spacer \\
\hline $4500-5000$ & 10 & LSC & matK rbcL & spacer \\
\hline $31,500-32,000$ & 10 & LSC & 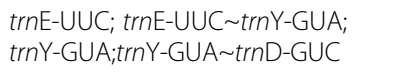 & $\begin{array}{l}\text { coding; spacer; coding; } \\
\text { spacer }\end{array}$ \\
\hline $33,500-34,000$ & 10 & LSC & psbM pet N; petN; petN trnC-GCA & spacer; coding; spacer \\
\hline $49,500-50,000$ & 10 & LSC & $a t p H ; a t p H \sim a t p F ; a t p F$ & coding; spacer; coding \\
\hline $58,000-58,500$ & 10 & LSC & $\operatorname{trnU} U-U U G \sim a c c D ; a c c D$ & spacer; coding \\
\hline $80,500-81,000$ & 10 & LSC & rps11; rps11 rp/36 & coding; spacer \\
\hline $101,500-102,000$ & 10 & IRA & rps7 trnV-GAC & spacer \\
\hline $123,000-123,500$ & 10 & SSC & $n d h A$ & coding \\
\hline
\end{tabular}


Table 4 The genome areas identified to be rich in indels among the twelve acquired chloroplast genomes. Genome areas that have more than 5 indels per $500 \mathrm{bp}$ are considered to be rich in indels

\begin{tabular}{|c|c|c|c|c|}
\hline Genome position & Count & Region & Genomic context & Content \\
\hline $57,000-57,500$ & 11 & LSC & $\operatorname{trnQ-UUG\sim accD}$ & spacer \\
\hline $115,500-116,000$ & 11 & SSC & $\begin{array}{l}r p / 32 \sim t r n L-U A G ; t r n L-U A G ; \\
\text { trnL-UAG cCSA }\end{array}$ & $\begin{array}{l}\text { spacer; coding; } \\
\text { spacer }\end{array}$ \\
\hline $66,000-66,500$ & 10 & LSC & psbE $\sim p e t \mathrm{~L}$ & spacer \\
\hline $123,000-123,500$ & 8 & SSC & $n d h \mathrm{~A}$ & coding \\
\hline $112,000-112,500$ & 7 & IRa;SSC & 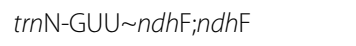 & spacer; coding \\
\hline $53,000-53,500$ & 6 & LSC & 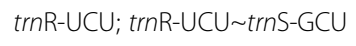 & coding; spacer \\
\hline $53,500-54,000$ & 6 & LSC & $\operatorname{trnR}-\mathrm{UCU} \sim \operatorname{trnS}-\mathrm{GCU}$ & coding \\
\hline $56,000-56,500$ & 6 & LSC & psbK; psbK trnQ-UUG & coding; spacer \\
\hline $10,000-10,500$ & 5 & LSC & $\operatorname{trn} \bigvee-U A C ; \operatorname{trn} \bigvee-U A C \sim n d h C$ & coding; spacer \\
\hline $13,000-13,500$ & 5 & LSC & $\begin{array}{l}n d h J \sim \operatorname{trnF}-\mathrm{GAA} ; \operatorname{trnF} \mathrm{F}-\mathrm{GAA} \\
\text { trnF-GAA }\end{array}$ & $\begin{array}{l}\text { spacer; coding; } \\
\text { spacer }\end{array}$ \\
\hline $29,500-30,000$ & 5 & LSC & psbD trnF-GGU & spacer \\
\hline $69,000-69,500$ & 5 & LSC & rps18; rps18 rps20 & coding; spacer \\
\hline $115,000-115,500$ & 5 & SSC & $r p / 32 ; r p / 32 \sim \operatorname{trn} L-U A G$ & coding; spacer \\
\hline $119,500-120,000$ & 5 & SSC & $p s a C \sim n d h \mathrm{E} ; n d h \mathrm{E} \sim n d h \mathrm{G}$ & spacer; spacer \\
\hline
\end{tabular}

this clade was 0.0606 Mya. The second sublineage (BS: 82; BPP: 1.0) within lineage II comprised three AA genome species (A. duranensis, A. hoehnei, A. villosa,), one KK (A. bartizocoi) and one EE genome species (A. paraguariensis). The split between these two sublineages might occur around 0.2078 Mya (Fig. 8).

\section{Discussion}

The close wild relatives have been contributing valuable genetic resources to many economically important crops [44-47]. This study successfully acquired the complete cp genomes of twelve Arachis species that are closely related to the cultivated peanut (A. hypogaea), which is one of the most important oilseed crops worldwide. The rich genetic resources associated with the twelve Arachis cp genome data may hold great potential for future peanut cultivar improvement.

The same to those of other land plants [48-50], the Arachis cp genome is a single circular molecule that displays a quadripartite structure (LSC, IRa, SSC, $\mathrm{IRb})$. Moreover, the genome size, gene composition and order, GC content, as well as IR-SC boundaries are also rather conserved among the Arachis cp genomes that have been acquired in this study (Additional file 1) and among thirteen earlier published Arachis cp genomes [21, 34-36]. Nevertheless, still substantial genetic variation (1368 SNDs and 311 indels) has been identified among the twelve acquired сp genomes, which, together with 69 SSR loci that have been detected in the present study, may serve as useful tools for future studies.

\section{The highly conserved IR regions}

Among the four cp genome regions, the two IR regions are highly conserved comparing to the two SC regions, as reflected by the fact that less than $8 \%$ of the SNDs, indels and SSRs that have been identified in this study are located within the IR regions even though IRa and IRb constitute about one third of the genome (Fig. 1, Table 2). This low level of genetic variation at the IR regions (Comparing to $\mathrm{SCs}$ ) is very common among plant species [51-53]. One possible explanation is that for the cp genome that exists as multiple copies within single plant cells, gene conversion with a tiny bias against new mutations would much more efficiently reduce the mutation load at the two IR (inverted repeat) regions than at the SC (single copy) regions due to the duplicative nature of the IRs [51, 52, 54-56]. Such conversion bias might arise from the base preference of the mismatch repair system during gene conversion $[54,57,58]$.

\section{Two major lineages within sect. Arachis}

There are two main genome types that have been identified within Sect. Arachis: AA (chromosome number: $2 n=20)$ and $B B(2 n=20)$, which are also very important because the tetraploid cultivated peanut has a complicated genome (AABB; $4 n=40$ ) that is composed of both of them [2]. Apart from AA, BB and AABB, Sect. Arachis species may also have a genome type of DD $(2 \mathrm{n}=$ $20)$, FF $(2 n=20)$, KK $(2 n=20)$ or aneuploidy $(2 n=18)$. Our phylogenetic analyses have shown that the analyzed Sect. Arachis taxa fall into two major lineages: the first one (lineage I) includes A. ipaënsis, which is the only BB genome species that has been studied here, as well as 


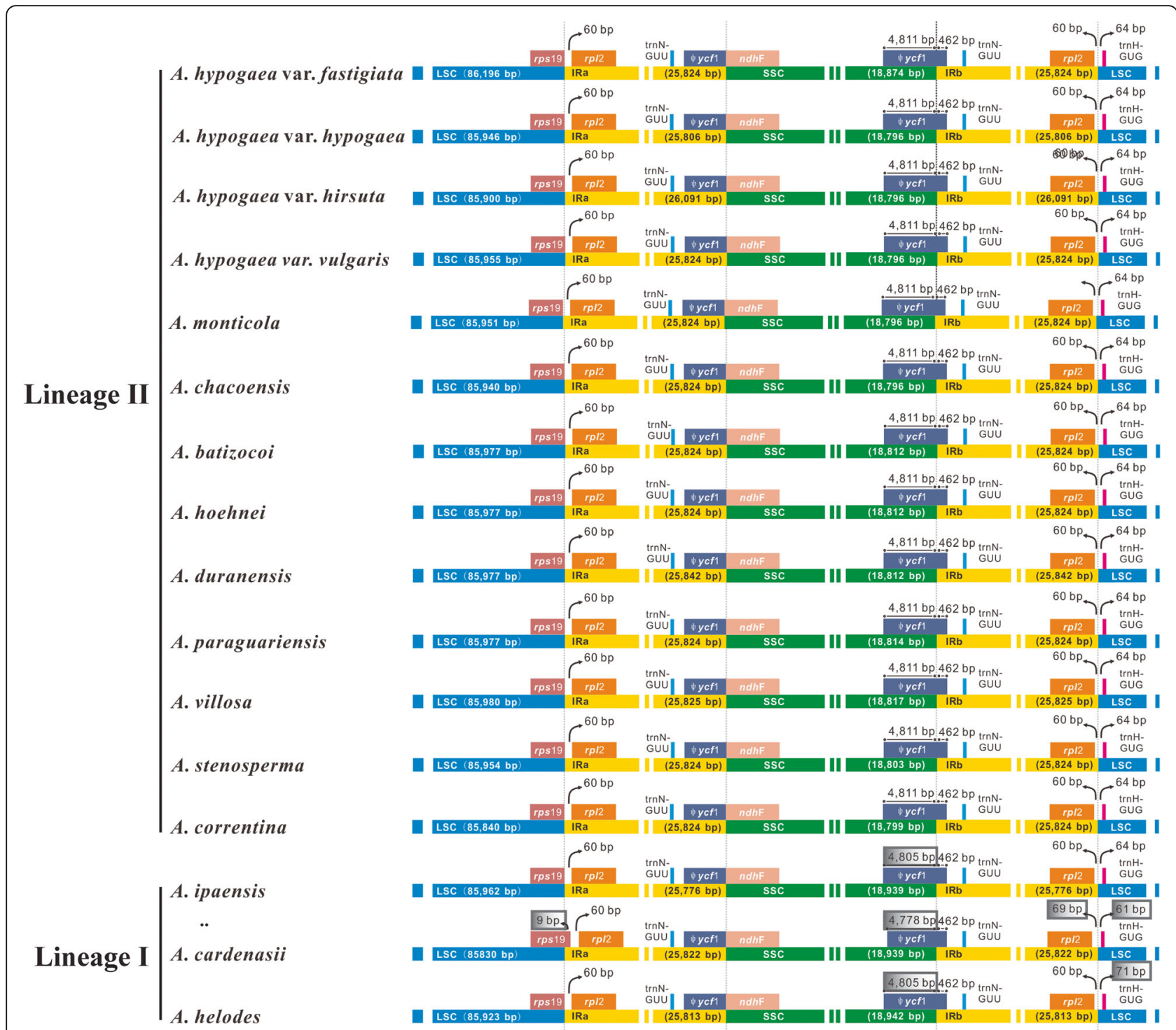

Fig. 3 Detailed view of the IR-SC border regions among the twelve studied Arachis species. Regions that differ from the majority are highligted in grey boxes, which, according to our phylogenetic analyses, all belong to species within lineage I

two AA genome species (Fig. 4). The second lineage (lineage II) comprises taxa that include two AABB genome species, six AA genome species, and one KK genome species. These two major lineages observed within Sect. Arachis are very well supported by bootstrap values (Fig. 4), if without the tetraploid A. hypogaea and $A$. monticola unifying them; they may be well distinguished as separate taxonomic sections $[1,20]$. Our divergence time estimation shows that the most recent common ancestor of these two major lineages is dated back to 0.818 Mya, and from this common ancestor lineage I was first derived (at least $0.6718 \mathrm{Mya}$ ), while lineage II was derived rather recently (0.2917 Mya) and rapidly (Fig. 8). The $\mathrm{cp}$ genome size and structure, the gene content and order, and the GC content are well conserved between the two lineages. However, the IR-SC border regions of the lineage I species cp genomes have been found to vary in length and differ from those of the lineage II species that are all identical (Fig. 3). The presence of two major Sect. Arachis lineages is confirmed by nuclear genome data generated by genotyping-by-sequencing (GBS) approach (unpublished observations).

Similar species grouping (into two major lineages) within Sect. Arachis has also been observed in a number of other studies (Additional file 4) [11, 14, 20-22, 24, 25, 59-62]. These studies may work on different Arachis species, and use very different methods, genetic markers or sequence data, but lineage II or the equivalent, in almost all of these studies, is dominated by the AA genome species and tends to exclude genome types other 


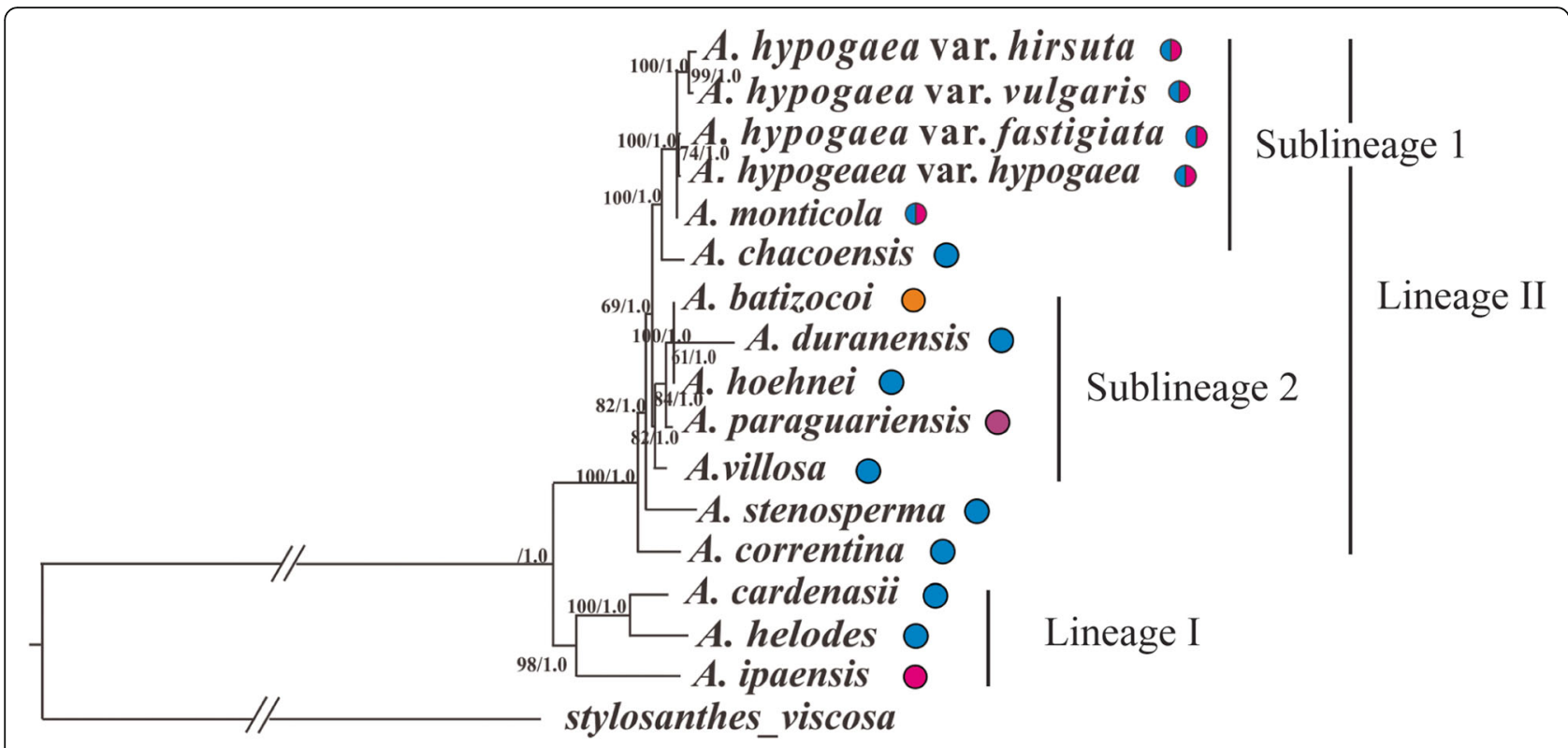

\section{Entire cp genome}

\section{Genome type OAABB OAA OBB OEE OKK}

Fig. 4 Bayesian inference tree for Arachis that is based on the entire cp genome. The tree is rooted with Stylosanthes viscosa. Two major lineages (I and II) have been observed among the Sect. Arachis species, and within lineage II, two sublineages (1 and 2) can also be recognized. For each node, the bootstrap support value is shown on the left and the Bayesian posterior probability is shown on the right. The genome type of each analyzed Arachis species are also given

than $\mathrm{AA}$ and $\mathrm{AABB}$ (Additional file 4). In contrast, lineage $I$ or the equivalent is more diverse and can take on any genome type (AA, BB, AABB, DD, FF, KK or aneuploidy) that has been identified within Sect. Arachis but slightly prefers the BB genome species (Additional file 4).

Interestingly, the AA genome species within Sect. Arachis are all perennial (except $A$. duranensis, A. stenosperma and $A$. hoehnei), while all the other various genome types (e.g. BB, DD, FF, KK and AABB) belong to annuals/ biennial species (Sect. Arachis is one of the only two Arachis sections that have annual species; the other one is Sect. Heteranthae) [4]. The genome type compositions of annual/biennial and perennial species may be consistent with the earlier finding that annual species generally have a much higher molecular evolutionary rate than perennial species [63-65]. Moreover, in the place of origin for Arachis, South America, the distribution areas of annual/ biennial species have relatively more diverse environmental conditions than those of perennial species. In South America, the overall geographic distribution of Sect. Arachis species has a bizarre shape that is kind of similar to a capital T [4]. The perennial Setc. Arachis species prevail the vertical axis of this $\mathrm{T}$ shaped range, which more or less coincides with the meridians $57^{\circ}$ and $58^{\circ}$ west and mainly includes the watersheds of the Paraguay and Uruguay rivers [4]. Whereas the annual/biennial species dominate the two arms of the "T" shaped geographic distribution: the Tocantins river to the east, the Mamoré river and the Guaporé river to the west, as well as the dry "charco" region (up to the foothills of the Andes) to the southwest [4]. At these arm regions, the annual/biennial species are usually adapted to very stressful environmental conditions, such as prolonged inundation and periodic drought [4].

Although the presence of two major lineages within Sect. Arachis and the overall pattern of the species component of these lineages are evident, however, to which lineage one Sect. Arachis species should be placed is not always clear. For example, according to the present study, the KK genome species, $A$. batizocoi, falls with most of the analyzed AA genome species into lineage II, however, $A$. batizocoi has been found to appear in lineage I-equivalent clade by three earlier chloroplast phylogenetic studies [14, $20,21]$. Another example is that the AA genome species $A$. cardenasii and $A$. helodes, which fall into lineage I at the present study, have, however, often been found in lineage II-equivalent clade by earlier studies [11, 20, 21, 60]. Moreover, A. paraguariensis (belonging to Sect. Erectoide), which is the only non-Sect. Arachis species acquired by the present study, was originally chosen as an 


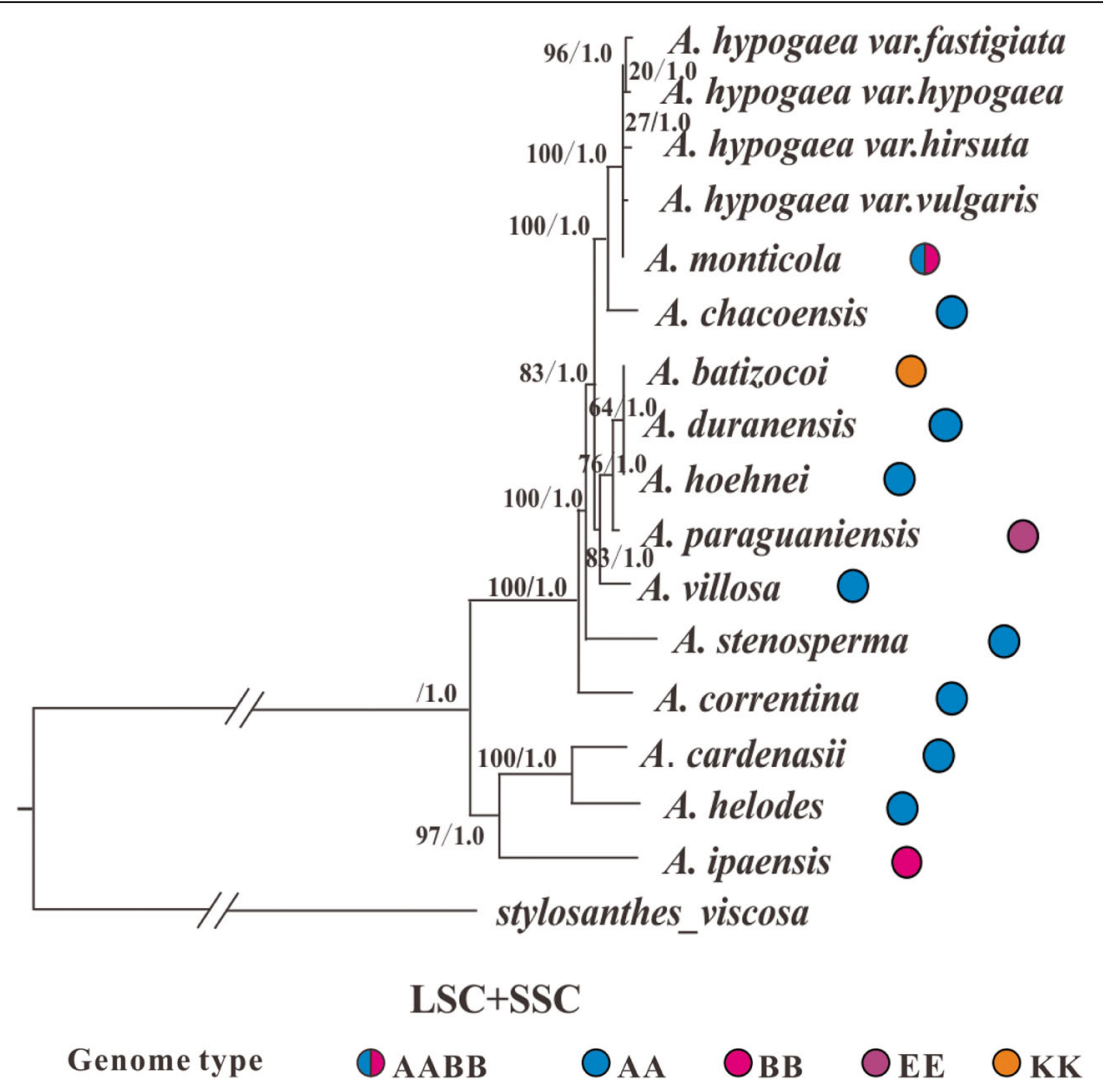

Fig. $\mathbf{5}$ Bayesian inference tree for Arachis that is based on the two single copy genome regions. The tree is rooted with Stylosanthes viscosa. For each node, the bootstrap support value is shown on the left and the Bayesian posterior probability is shown on the right. The genome type of each analyzed Arachis species are also given. A. chacoensis is now known as A. diogoi

outgroup but turned out to be closely related to A. batizocoi (KK), A. hoehnei (AA) and A. duranensis (AA) within lineage II (Fig. 4). It is worth noting that similar species mixing between Arachis sections are not uncommon [11, 20, 21, 24, 66]. For example, Yin et al. [21] studied seven Arachis species, five of which belong to Sect. Arachis while the rest two are the members of Sect. Procumbentes; instead of grouping together, the two Sect. Procumbentes species were, respectively, nested within different Sect. Arachis species groups.

These incongruences of species relationship that are mentioned above may be the result of several different reasons. First, a high level of genetic variation has been reported within different Arachis species (especially the wild ones) $[4-10,67]$. This high level of intraspecific genetic variation may be at least partly due to the autogamous reproductive system and the underground fruiting habit of the Arachis species, which can seriously restrain interspecific and intraspecific gene flows [4]. Therefore, different samples of the same species may have distinct genetic constitution (such as A. duranensis, see below) and phylogeny inference based on these different samples is then likely to result in very different species relationship, for this reason, more representative samples from each species need to be considered for future phylogenetic study. Second, Arachis species are not always completely incompatible with each other, hybridization even between different genome types or sections have been well documented $[2,14,15,59]$; the interspecific hybrids that are possibly produced in nature may well blur the species boundaries. Third, considering the rather recent divergence of the Sect. Arachis species ( $<1$ Mya, Fig. 8), ancestral polymorphism is also likely to be maintained within extant species and consequently complicate phylogeny inference. In addition, differences in analyzing method (such as UPGMA and maximum likelihood), in genetic data type (AFLP, RFLP and DNA sequence etc.), in the amount of genetic information that is considered (single genes or genome data), as well as in the inheritance mode (bi-parental or uni-parental) of the acquired data set will all have an impact on the inference of species relationship [29].

\section{The maternal origin of the cultivated peanut ( $A$. hypogeae)}

Between the two major Sect. Arachis lineages that have been observed from the phylogenetic trees inferred by the 


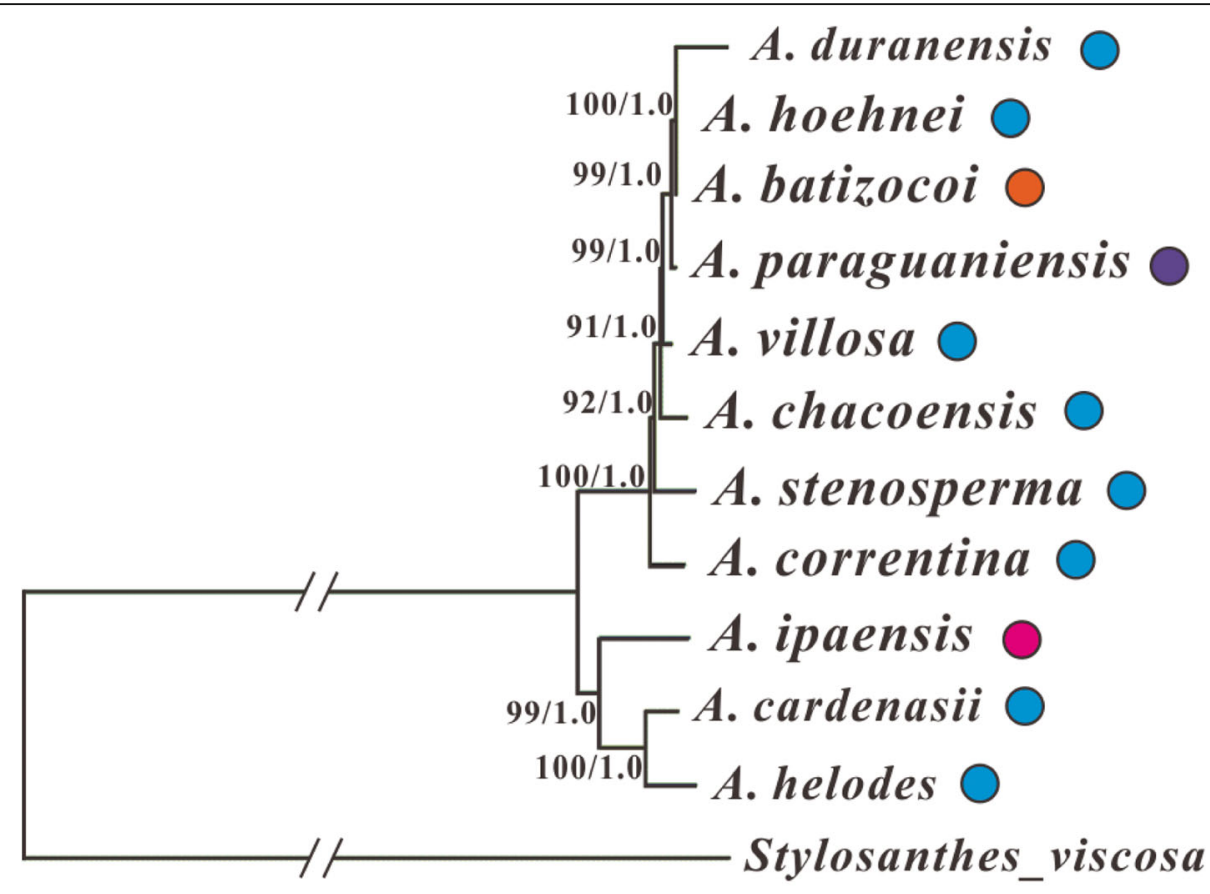

\section{Diploid Arachis}

\section{Genome type OAA ОВB ОЕЕ ОKK}

Fig. 6 Bayesian inference tree for Arachis that only considers the diploid species. The tree is based on the entire cp genome and rooted with Stylosanthes viscosa. For each node, the bootstrap support value is shown on the left and the Bayesian posterior probability is shown on the right. The genome type of each analyzed Arachis species are also given. A. chacoensis is now known as A. diogoi

present study, it is lineage II that the cultivated peanut falls into, and within this group, the four considered $A$. hypogeae varieties mix together with $A$. monticola. This result is not in conflict with previous views that $A$. monticola may be the direct wild ancestor of the cultivated peanut [11] or as an introgressive derivative between the cultivated peanut and wild Arachis species [68, 69]. These earlier views are based on a combination of different evidences. For example, these two species are the only tetraploid species within Sect. Arachis and they usually group together in phylogenetic analyses $[2,26,66]$. Moreover, the geographic distributions of these two species are close to each other [70] and hybridization between them has been well documented $[14,16]$.

From the discussion above, we have already known that lineage II or the equivalent is dominated by AA genome species and particularly "disfavors" BB genome species, and this is especially true for the phylogenetic trees that are inferred from cp sequences as reflected by the present and three earlier studies [14, 20, 21]. Actually in all of these four studies, the cultivated peanut is nested within lineage II or the equivalent. Considering the chloroplast genome is maternally inherited in Arachis as shown by an earlier study, where the F1 hybrids between two Arachis species always grouped together with their maternal parents in the phylogenetic tree that was built based on chloroplast DNA [14], our result suggests that the maternal genome donor to the tetraploid cultivated peanut $(\mathrm{AABB})$ and the tetraploid wild peanut species (A. monticola; AABB) is one AA genome species [14, 20,71], or one can say that the A genome of $A$. hypogeae and $A$. monticola is contributed by their maternal progenitor.

Currently, the most popular view regarding exactly which species serve as the genome donors to $A$. hypogeae and $A$. monticola is that $A$.duranensis (AA) and A. ipaënsis (BB) contribute, respectively, the $\mathrm{A}$ and $\mathrm{B}$ genomes. This generally accepted opinion is supported by evidences from genome type, geographic distribution, crossability, cytogenetic analysis, molecular analysis, phylogenetic analysis and genome sequence comparison $[11,14,43,60,70-72]$. However, in the present study, A. hypogeae and A. monticola group closely with neither $A$. duranensis nor $A$. ipaënsis in the inferred phylogenetic tree (Fig. 4), instead, these two tetraploid species form a well-supported subgroup with $A$. chacoensis (AA). Our result alone, however, cannot conclude that $A$. chacoensis, instead of $A$. duranensis, serves as 
the A genome donor to A. hypogeae and A. monticola due to a combination of different reasons. First of all, A. duranensis has a relatively wide geographical distribution and lots of intraspecific variation has been reported within this species $[8,22,71,72]$, if different samples that have distinct genetic makeups are used for phylogenetic inference, the result may be very different. Next, $A$. duranensis has been shown to be able to hybridize with other Arachis species [14], leading to interspecific gene flow that may also blur the species boundary. At last, although chloroplast genomes have a lot of advantages in phylogenetic analysis as mentioned in Introduction, they are however relatively vulnerable to problems like introgression and the retention of ancestral polymorphism that are frequently encountered when inferring the phylogenetic relationship between closely related species, due to their maternal inheritance mode [73, 74].

\section{Conclusions}

The highly variable wild peanut species may serve as a rich source of useful alleles for the improvement of the cultivated peanut, which is one of the most important oilseed crops in the world. The present study has acquired the complete cp genome sequences of twelve Arachis species and eleven of which belong to Sect. Arachis; the cultivated peanut is also a member of Sect. Arachis. As for other land plant species [48-50], the cp genome size and structure, as well as gene content and order are highly conserved among the twelve acquired cp genomes. Nevertheless, substantial SNDs, indels and SSRs have been identified from the acquired genomes, and most of these SNDs, indels, and SSRs are distributed at the two single copy genome regions (LSC and SSC). The two inverted repeat genome regions (IRa and IRb) have a very low level of genetic variation, which may be due to biased gene conversions. Phylogenetic analyses of the acquired genomes have identified two major lineages (I and II) within Sect. Arachis. Our results together with many earlier studies show that lineage II is dominated by AA genome species that are mostly perennial while the genome types of the lineage I species are rather diverse; Sect. Arachis species with genome types other than AA are all annual/biennial [4]. In addition, the tetraploid cultivated peanut is found within lineage II, which together with the maternal inheritance mode of chloroplast suggest that it is an AA genome species that served as the maternal donor of the cultivated peanut. In summary, the twelve cp genomes acquired in the present study have not only helped us understand the genetic basis and phylogenetic relationships of the Arachis species better, but also provided us with substantial genetic resources that may be valuable for future peanut improvement.

\section{Methods}

\section{Plant material and genome sequencing}

A total of twelve Arachis species that belong to Sect. Arachis (A. monticola, A. duranensis, A. stenosperma, A. batizocoi, A. cardenasii, A. helodes, A. correntina, A. hoehnei, A. chacoensis (now known as $A$. diogoi) and $A$. villosa, $A$. ipaënsis) and Sect. Erectoides (A. paraguariensis ssp. paraguariensis) were included in the present study (Table 1). The seeds for these wild peanut species (except $A$. ipaënsis, see below) originally came from, and were identified as well by, the National Wild Arachis Nursery, Oil Crop Research Institute, Chinese Academy of Agricultural Sciences, Wuhan, China. All the analyzed species have an AA genome type, except A. batizocoi (KK), A. ipaënsis (BB), and $A$. paraguariensis (EE) [2]. Leaves from single one-month-old plants representing each of these species (except A. ipaënsis) (grown under greenhouse conditions) were collected for total genomic DNA isolation using the DNeasy Plant Mini Kit (QIAGEN, Germany). DNA quality was checked by agarose gel electrophoresis using Super GelRed dye (US Everbright Inc., Suzhou, China). A single paired-end library with an average insert size of about $350 \mathrm{bp}$ was constructed for all analyzed samples (different species are "indexed" with different barcoded adapters) following the manufacturer's protocol (Illumina, Beijing, China). The constructed library first had its quality assessed on Caliper LabChip GX using the High Sensitivity Assay Kit (Caliber, USA), and was then hybridized and amplified on a flow cell to generate clonal clusters on the $\mathrm{CBOT}$ platform using the Truseq PE Cluster Kit v3-cBot-HS (Illumina, Beijing, China). Whole-cp genome sequencing by synthesis was performed on the Illumina Hiseq Xten platform using the Truseq v3HS kit (Illumina, Beijing, China).

\section{Genome assembly and annotation}

The Illumina sequencing generated $>1 \mathrm{~Gb}$ raw paired-end reads for each sample, and these data were deposited into NCBI Sequence Read Archive (SRA) (BioProject Accession No. PRJNA543570). These raw paired-end reads, plus one raw read dataset for $A$. ipaënsis that was downloaded from the NCBI SRA database (accession number: SRX2701518) [37], were analyzed using the NGS QC ToolKit v2.3.3 for filtering low quality data after quality check and removing adaptor sequences [75]; the cut-off values for the percentage of read length and phred score were set, respectively, to 80 and 30. In total, 305,336-3,503,151 high-quality reads were acquired per sample, which produced 293-3362 fold cp genome coverage when being mapped onto a reference cp genome from A. hypogaea (GenBank [76] accession number KX257487, [35]) using bowtie [77] (Additional file 1). The high-quality reads (obtained from last step) that belong to the cp genome were extracted and assembled into contigs using the de novo assembler SPAdes v3.9.0 [78] (with several different k-mer sizes: 93, 105, 117 and 121). 
These assembled contigs were further assembled into complete cp genomes by NOVOPlasty v2.6.2, which has been designed specifically for assembling organelle genomes [79]. The complete cp genome was annotated using the DOGMA tool with default parameters [80]. OGDraw v1.2 [81] was used to draw complete cp genome images.

For each of the assembled complete cp genomes, with the help of the sequin software [82], a SQN file was generated. The SQN file was then submitted to GenBank (accession numbers: MK144818 for A. monticola, MK144823 for A. paraguariensis, MK144822 for A. duranensis, MK144 819 for A. stenosperma, MK144820 for A. batizocoi, MK14 4824 for $A$. cardenasii, MK144826 for A. helodes, MK14 4828 for A. correntina, MK144827 for A. hoehnei, MK144 821 for A. chacoensis (now known as A. diogoi), MK144829 for A. ipaënsis and MK144825 for A. villosa).

\section{Genetic variation analysis}

Both SNDs and indels were detected from the mapping (to the $A$. hypogaea reference genome) results of the bowtie analyses (see above) using GATK [83] (ploidy setting =1). The VISTA server [84] was used to identify the conserved genome regions. The visualization of the densities of SNDs and indels (i.e. the number of SNDs or indels counted for every consecutive $500 \mathrm{bp}$ blocks), and the conserved regions over the entire cp genome were performed using Circos [85]. Simple sequence repeats (SSRs) were predicted using MISA [86] with default parameters except the minimum counts of the repeat unit within single SSR motifs: (10) mono-, (6) di-, (5) tri-, (4) tetra-, (3) penta-, and (3) hexanucleotide repeat units [21]. All the identified SSRs were manually checked and redundant results were removed.

\section{Phylogenetic analysis and divergence time estimation}

To better understand the species relationships within Arachis, especially within Sect. Arachis, phylogenetic analyses were performed on the complete cp genome data. Apart from the twelve $\mathrm{cp}$ genomes that were acquired by the present study, four earlier published cp genomes from different A. hypogeae botanical varieties (GenBank accession no. MG814006 for var. fastigiata Waldron, MG814007 for var. hirsute Kohler, MG814008 for var. hypogaea L., MG814009 for var. vulgaris Harz) [36] were also included in the analyses, so, in total 16 complete cp genomes from thirteen Arachis species were considered for the phylogenetic inference. In addition, a cp genome of Stylosanthes viscosa L. (GenBank accession no. MG735675) was chosen as an outgroup for the phylogenetic analysis; this cp genome showed the highest similarity to Arachis species [87] among the cp genomes that were available up to the date when the analysis was performed. Before being used for the phylogenetic analyses, the $17 \mathrm{cp}$ genomes were aligned with the HolmBlocks pipeline (with default settings unless specified) [88], which was fast and efficient especially for handling a large amount of divergent interspecies sequence data and was therefore suitable for overcoming the alignment difficulties that may be introduced by the relatively distantly related outgroup species. Within the HolmBlocks pipeline, progressiveMauve [89] was first used to identify conserved genome regions, based on which a preliminary alignment was next constructed; the alignment was then trimmed by Gblocks [90] to remove poorly aligned and divergent regions.

The phylogenetic analyses were first carried out using the Maximum Likelihood methods as implemented in IQTREE [91]. Ten independent searches were performed, and the statistical confidence in each predicted node was evaluated with 10,000 non-parametric bootstrap replicates. MrBayes v3.2.5 [92] was then used to perform Bayesian inferences of phylogeny via Markov Chain Monte Carlo method [92]. We run the inferences for 100,000 Markov Chain Monte Carlo generations, with a sampling frequency of 1000 generations. Results of the first $25 \%$ generations were discarded as burn-ins and the rest were used to build a $50 \%$ majority-rule consensus tree.

Land plant cp genomes were characterized by four typical regions: two IR regions and two $\mathrm{SC}$ regions, (see Results) [38]. The IR regions were shown to have a much lower nucleotide substitution rate comparing with the SC regions [52, 54, 93], so might not be suitable for inferring the phylogeny of the closely related Sect. Arachis species as analyzed by the present study. Here, we therefore reconstructed the phylogeny using the same methods as above but excluding the IR regions.

Phylogenetic analyses of species differing in ploidy levels might produce unusual results comparing to those only involving species with the same ploidy level $[1,20]$, in order to test whether this is the case with our study, we then excluded the two tetraploid species (A. hypogeae and $A$. monticola) and only used the diploid species for inferring phylogenetic trees with whole genome data.

Moreover, indels were not considered in the abovementioned phylogenetic analyses, however, information that was embedded within indels might help improve the resolution of phylogeny for recently divergent species [42]. We therefore performed the last phylogenetic analysis (for this study) that took the 311 indels observed in our Arachis whole-genome data into consideration. In this step, the indels were first converted into binary data with the simple indel coding method [94] using the SeqState software [95]. The acquired binary data together with the ordinary nucleotide substitution information were input into MrBayes as mixed data for Bayesian inferences of Arachis phylogeny.

At last, the software BEAST v1.7.2 [96] was used to estimate the divergence time among different Arachis species. The estimated divergence time between genus Stylosanthes and Arachis from Saslis-Lagoudakis et al. [97] was used as a calibration point. 


\section{Supplementary information}

Supplementary information accompanies this paper at https://doi.org/10. 1186/s12870-019-2121-3.

Additional file 1. Basic characteristics of the twelve Arachis genomes that have been acquired in this study. A. chacoensis is now known as $A$. diogoi.

Additional file 2. The genes that have been identified from the twelve acquired chloroplast genomes. Intron-containing genes are marked by asterisks $(*)$.

Additional file 3. The SSR makers that have been developed from the twelve acquired Arachis chloroplast genomes.

Additional file 4. A summary of earlier studies that have identified two major Sect. Arachis lineages.

\section{Abbreviations}

BPP: Bayesian posterior probability; BS: bootstrap; cp: chloroplast; indel: insertion/deletion; IR: inverted repeat (region); IRa, IRb: two IR regions that are identical but in opposite orientations; LSC: long single copy (region); Mya: million years ago; SC: single copy (region); SND: single nucleotide divergence; SSC: short single copy (region)

\section{Acknowledgements}

The authors would like to thank Prof. Ronghua Tang and Dr. Liangqiong He from the Nanning Branch of National Field Genebank, Guangxi Academy of Agricultural Sciences as well as Prof. Huifang Jiang from the Oil Crop Research Institute, Chinese Academy of Agricultural Sciences for their help with our wild peanut materials. We would also like to thank Dr. Dachuan Shi from Qingdao Academy of Agricultural Sciences of China and Dr. Guiqi Bi from Sun Yat-sen University of China for their excellent advice on earlier versions of this paper.

\section{Authors' contributions}

JW and SS conceived and designed the study; JW, CY1 (Caixia Yan), QS and CS performed the experiments; JW, YL, CY2 (Cuiling Yuan), XZ and CL analyzed the data; JW and $Y L$ prepared figures and/or tables; JW and $Y L$ wrote the manuscript; JW, YL and SS critically revised the manuscript. All authors read and approved the final manuscript.

\section{Funding}

This work was supported by the Specific Funds of the Central Guidance for Local Science and Technology, the Natural Science Foundation of Shandong Province (ZR2017BC082), the Taishan Scholars Project (ts201712080), the Agro-industry Technology Research System of Shandong Province (SDAIT-0402), the Fine Breeding Project of Shandong Province (2017LZGC003, 2017LZGC033). Yuan Li would like to thank financial support from Stiftelsen Olle ENGKVIST Byggmästare (2017_185-606). The funders had no role in the design of the study and collection, analysis, and interpretation of data and in writing the manuscript.

\section{Availability of data and materials}

The plant samples that are used in the present study are available from the corresponding author on reasonable request. The datasets that have been generated (assembled complete chloroplast genome accession numbers: MK144818 for Arachis monticola, MK144823 for A. paraguariensis, MK144822 for A. duranensis, MK144819 for A. stenosperma, MK144820 for A. batizocoi, MK144824 for A. cardenasii, MK144826 for A. helodes, MK144828 for A. correntina, MK144827 for A. hoehnei, MK144821 for A. chacoensis, MK144829 for A. ipaënsis and MK144825 for A. villosa) or analyzed (raw reads of chloroplast genome: SRX2701518 for A. ipaënsis; cultivated peanut chloroplast genomes: KX257487, MG814006, MG814007, MG814008, MG814009) for this study can be found in GenBank (https://www.ncbi.nlm. nih.gov/genbank). The raw data supporting the conclusions of this manuscript, the Maximum Likelihood trees built in this study, the phylogenetic tree based on nuclear genome data generated by genotypingby-sequencing (GBS) approach (unpublished observations) are available from the corresponding author on reasonable request. All the other datasets for this study are included in the manuscript and the additional files.

\section{Ethics approval and consent to participate}

The collection of $A$. helodes predates the need for permission to collect.

Consent for publication

Not applicable.

\section{Competing interests}

The authors declare that they have no competing interests.

\section{Author details}

'Shandong Peanut Research Institute, Qingdao, China. ${ }^{2}$ Computational Biology and Biological Physics, Astronomy and Theoretical Physics, Lund University, Lund, Sweden.

Received: 21 January 2019 Accepted: 5 November 2019 Published online: 19 November 2019

\section{References}

1. Bertioli DJ, Seijo G, Freitas FO, Valls JF, Leal-Bertioli SCM, Moretzsohn MC. An overview of peanut and its wild relatives. Plant Genet Resour. 2011;9:134-49.

2. Stalker HT. Utilizing wild species for peanut improvement. Crop Sci. 2017;57: 1102-20.

3. Yu SCW. Peanut varieties and their genealogy in China. Shanghai, China: Shanghai scientific and Technical publishers; 2008.

4. Krapovickas A, Gregory WC, Williams DE, Simpson CE. Taxonomy of the genus Arachis (Leguminosae). Bonplandia. 2007;16:7-205.

5. Halward TM, Stalker HT, Larue EA, Kochert G. Genetic variation detectable with molecular markers among unadapted germ-plasm resources of cultivated peanut and related wild species. Genome. 1991;34:1013-20.

6. Hilu KW, Stalker HT. Genetic relationships between peanut and wild species of Arachis sect. Arachis (Fabaceae): evidence from RAPDs. Plant Syst Evol. 1995:198:167-78.

7. Kochert G, Halward T, Branch WD, Simpson CE. RFLP variability in peanut (Arachis hypogaea L.) cultivars and wild species. Theor Appl Genet. 1991;81: 565-70.

8. Milla SR, Isleib TG, Stalker HT. Taxonomic relationships among Arachis sect. Arachis species as revealed by AFLP markers. Genome. 2005;48:1-11.

9. Paik-Ro OG, Smith RL, Knauft DA. Restriction fragment length polymorphism evaluation of six peanut species within the Avachis section. Theor Appl Genet. 1992;84:201-8.

10. de Carvalho MM, Hopkins MS, Mitchell SE, Kresovich S, Valls JFM, Ferreira ME. Genetic diversity of peanut (Arachis hypogaea L.) and its wild relatives based on the analysis of hypervariable regions of the genome. BMC Plant Biol. 2004;4:11

11. Moretzsohn MC, Gouvea EG, Inglis PW, Leal-Bertioli SCM, Valls JFM, Bertioli DJ. A study of the relationships of cultivated peanut (Arachis hypogaea) and its most closely related wild species using intron sequences and microsatellite markers. Ann Bot. 2012;111:113-26.

12. Fonceka D, Tossim H-A, Rivallan R, Vignes $H$, Lacut $\mathrm{E}$, de Bellis F, Faye I, Ndoye O, Leal-Bertioli SC, Valls JF. Construction of chromosome segment substitution lines in peanut (Arachis hypogaea L.) using a wild synthetic and QTL mapping for plant morphology. PLoS One. 2012;7:e48642.

13. Leal-Bertioli SCM, Godoy IJ, Santos JF, Doyle JJ, Guimarães PM, Abernathy BL, Jackson SA, Moretzsohn MC, Bertioli DJ. Segmental allopolyploidy in action: increasing diversity through polyploid hybridization and homoeologous recombination. Am J Bot. 2018;105:1053-66.

14. Tallury SP, Hilu KW, Milla SR, Friend SA, Alsaghir M, Stalker HT, Quandt D. Genomic affinities in Arachis section Arachis (Fabaceae): molecular and cytogenetic evidence. Theor Appl Genet. 2005;111:1229-37.

15. Fávero AP, Simpson CE, Valls JFM, Vello NA. Study of the evolution of cultivated peanut through crossability studies among Arachis ipaënsis, A. duranensis, and A. hypogaea. Crop Sci. 2006;46:1546-52.

16. Krapovickas A, Gregory WC. Taxonomia del genero "Arachis (Leguminosae)". Bonplandia. 1994:1-186

17. Mota APZ, Vidigal B, Danchin EGJ, Togawa RC, Leal-Bertioli SCM, Bertioli DJ, Araujo ACG, Brasileiro ACM, Guimaraes PM. Comparative root transcriptome of wild Arachis reveals NBS-LRR genes related to nematode resistance. BMC Plant Biol. 2018;18:159

18. Fernández A, Krapovickas A Cromosomas y evolucion en "Arachis (leguminosae)". Bonplandia. 1994;8:187-220. 
19. Valls JFM, Simpson CE. New species of Arachis (leguminosae) from Brazil. Paraguay and Bolivia Bonplandia. 2005;14:35-63.

20. Friend SA, Quandt D, Tallury SP, Stalker HT, Hilu KW. Species, genomes, and section relationships in the genus Arachis (Fabaceae): a molecular phylogeny. Plant Syst Evol. 2010;290:185-99.

21. Yin DM, Wang $Y$, Zhang $X G, M a X L$, He XY, Zhang JH. Development of chloroplast genome resources for peanut (Arachis hypogaea L.) and other species of Arachis. Sci Rep. 2017;7:11649.

22. Gimenes MA, Lopes CR, Valls JFM. Genetic relationships among Arachis species based on AFLP. Genet Mol Biol. 2002;25:349-53.

23. Barkley NA, Dean RE, Pittman RN, Wang ML, Holbrook CC, Pederson GA. Genetic diversity of cultivated and wild-type peanuts evaluated with M13tailed SSR markers and sequencing. Genet Res. 2007;89:93-106.

24. Wang CT, Wang XZ, Tang YY, Chen DX, Cui FG, Zhang JC, Yu SL. Phylogeny of Arachis based on internal transcribed spacer sequences. Genet Resour Crop Evol. 2011;58:311-9.

25. Bechara MD, Moretzsohn MC, Palmieri DA, Monteiro JP, Bacci M Jr, Martins J Jr, Valls JF, Lopes CR, Gimenes MA. Phylogenetic relationships in genus Arachis based on ITS and 5.8 S rDNA sequences. BMC Plant Biol. 2010;10:255.

26. Vishwakarma MK, Kale SM, Sriswathi M, Naresh T, Shasidhar Y, Garg V, Pandey MK, Varshney RK. Genome-wide discovery and deployment of insertions and deletions markers provided greater insights on species, genomes, and sections relationships in the genus Arachis. Front Plant Sci. 2017:8:2064.

27. Daniell H, Lin C-S, Yu M, Chang W-J. Chloroplast genomes: diversity, evolution, and applications in genetic engineering. Genome Biol. 2016;17:134.

28. Wu Z-Q, Ge S. The phylogeny of the BEP clade in grasses revisited: evidence from the whole-genome sequences of chloroplasts. Mol Phylogenet Evol. 2012;62:573-8

29. Delsuc F, Brinkmann H, Philippe H. Phylogenomics and the reconstruction of the tree of life. Nat Rev Genet. 2005;6:361-75.

30. Lanier HC, Knowles LL. Is recombination a problem for species-tree analyses? Syst Biol. 2012;61:691-701.

31. Birky CW Jr. The inheritance of genes in mitochondria and chloroplasts: laws, mechanisms, and models. Annu Rev Genet. 2001;35:125-48.

32. Hao DC, Chen SL, Xiao PG. Molecular evolution and positive Darwinian selection of the chloroplast maturase matK. J Plant Res. 2010;123:241-7.

33. Peng LW, Yamamoto H, Shikanai T. Structure and biogenesis of the chloroplast NAD(P)H dehydrogenase complex. Biochim Biophys ActaBioenerg. 1807;2011:945-53.

34. Schwarz EN, Ruhlman TA, Sabir JSM, Hajrah NH, Alharbi NS, Al-Malki AL, Bailey $C D$, Jansen RK. Plastid genome sequences of legumes reveal parallel inversions and multiple losses of rps 16 in papilionoids. J Syst Evol. 2015;53:458-68.

35. Prabhudas SK, Prayaga S, Madasamy P, Natarajan P. Shallow whole genome sequencing for the assembly of complete chloroplast genome sequence of Arachis hypogaea L. Front Plant Sci. 2016;7:1106.

36. Wang J, Li CJ, Yan CX, Zhao XB, Shan SH. A comparative analysis of the complete chloroplast genome sequences of four peanut botanical varieties. Peerj. 2018;6:e5349.

37. University-of-Georgia. DNA-seq of A. ipaënsis: leaf. 2018. https://www.ncbi. nlm.nih.gov/sra/SRX2701518.

38. Cui LY, Leebens-Mack J, Wang L-S, Tang JJ, Rymarquis L, Stern DB, DePamphilis CW. Adaptive evolution of chloroplast genome structure inferred using a parametric bootstrap approach. BMC Evol Biol. 2006;6:13.

39. Goulding SE, Olmstead RG, Morden CW, Wolfe KH. Ebb and flow of the chloroplast inverted repeat. Mol Gen Genet. 1996;252:195-206.

40. Kuang D-Y, Wu H, Wang Y-L, Gao L-M, Zhang S-Z, Lu L. Complete chloroplast genome sequence of Magnolia kwangsiensis (Magnoliaceae): implication for DNA barcoding and population genetics. Genome. 2011;54:663-73.

41. Huang H, Shi C, Liu Y, Mao S-Y, Gao L-Z. Thirteen Camellia chloroplast genome sequences determined by high-throughput sequencing: genome structure and phylogenetic relationships. BMC Evol Biol. 2014;14:151.

42. Redelings BD, Suchard MA. Incorporating indel information into phylogeny estimation for rapidly emerging pathogens. BMC Evol Biol. 2007;7:40.

43. Bertioli DJ, Cannon SB, Froenicke L, Huang GD, Farmer AD, Cannon EKS, Liu X, Gao DY, Clevenger J, Dash S, et al. The genome sequences of Arachis duranensis and Arachis ipaënsis, the diploid ancestors of cultivated peanut. Nat Genet. 2016:48:438-46.

44. Brozynska M, Furtado A, Henry RJ. Genomics of crop wild relatives: expanding the gene pool for crop improvement. Plant Biotechnol J. 2016; 14:1070-85.

45. Prohens J, Gramazio P, Plazas M, Dempewolf H, Kilian B, Díez MJ, Fita A, Herraiz FJ, Rodríguez-Burruezo A, Soler S. Introgressiomics: a new approach for using crop wild relatives in breeding for adaptation to climate change. Euphytica. 2017;213:158

46. Dempewolf H, Baute G, Anderson J, Kilian B, Smith C, Guarino L. Past and future use of wild relatives in crop breeding. Crop Sci. 2017;57:1070-82.

47. Zhang H, Mittal N, Leamy L, Barazani O, Song BH. Back into the wild-apply untapped genetic diversity of wild relatives for crop improvement. Evol Appl. 2017;10:5-24.

48. Yurina NP, Sharapova LS, Odintsova MS. Structure of plastid genomes of photosynthetic eukaryotes. Biochem Mosc. 2017;82:678-91.

49. Odintsova MS, Yurina NP. Plastid genomes of higher plants and algae: structure and functions. Mol Biol. 2003;37:649-62.

50. Khan A, Khan IA, Asif H, Azim MK. Current trends in chloroplast genome research. Afr J Biotechnol. 2010;9:3494-500.

51. Perry AS, Wolfe KH. Nucleotide substitution rates in legume chloroplast DNA depend on the presence of the inverted repeat. J Mol Evol. 2002;55: 501-8.

52. Zhu A, Guo W, Gupta S, Fan W, Mower JP. Evolutionary dynamics of the plastid inverted repeat: the effects of expansion, contraction, and loss on substitution rates. New Phytol. 2016;209:1747-56.

53. Chaw S-M, Wu C-S, Sudianto E. Evolution of gymnosperm plastid genomes. Adv Bot Res. 2018;85:195-222.

54. Birky CW, Walsh JB. Biased gene conversion, copy number, and apparent mutation rate differences within chloroplast and bacterial genomes. Genetics. 1992;130:677-83.

55. Li F-W, Kuo L-Y, Pryer KM, Rothfels CJ. Genes translocated into the plastid inverted repeat show decelerated substitution rates and elevated GC content. Genome Biol Evol. 2016;8:2452-8.

56. Wu C-S, Chaw S-M. Evolutionary stasis in cycad plastomes and the first case of plastome GC-biased gene conversion. Genome Biol Evol. 2015:7:2000-9.

57. Nagylaki T, Petes TD. Intrachromosomal gene conversion and the maintenance of sequence homogeneity among repeated genes. Genetics. 1982;100:315-37.

58. Walsh JB. Role of biased gene conversion in one-locus neutral theory and genome evolution. Genetics. 1983;105:461-8.

59. Leal-Bertioli SCM, Santos SP, Dantas KM, Inglis PW, Nielen S, Araujo ACG, Silva JP, Cavalcante U, Guimaraes PM, Brasileiro ACM. Arachis batizocoi: a study of its relationship to cultivated peanut (a. hypogaea) and its potential for introgression of wild genes into the peanut crop using induced allotetraploids. Ann Bot. 2014;115:237-49.

60. Jung S, Tate PL, Horn R, Kochert G, Moore K, Abbott AG. The phylogenetic relationship of possible progenitors of the cultivated peanut. J Hered. 2003; 94:334-40.

61. He GH, Barkley NA, Zhao YL, Yuan M, Prakash CS. Phylogenetic relationships of species of genus Arachis based on genic sequences. Genome. 2014;57: 327-34.

62. da Cunha FB, Nobile PM, Hoshino AA, de Carvalho MM, Lopes CR, Gimenes MA. Genetic relationships among Arachis hypogaea L. (AABB) and diploid Arachis species with AA and BB genomes. Genet Resour Crop Evol. 2008;55:15-20.

63. Bousquet J, Strauss SH, Doerksen AH, Price RA. Extensive variation in evolutionary rate of $r b c L$ gene sequences among seed plants. Proc Natl Acad Sci U S A. 1992:89:7844-8.

64. Andreasen K, Baldwin BG. Unequal evolutionary rates between annual and perennial lineages of checker mallows (Sidalcea, Malvaceae): evidence from 18S-26S rDNA internal and external transcribed spacers. Mol Biol Evol. 2001; 18:936-44.

65. Laroche J, Bousquet J. Evolution of the mitochondrial rps3 intron in perennial and annual angiosperms and homology to nad5 intron 1. Mol Biol Evol. 1999;16:441-52.

66. Koppolu R, Upadhyaya HD, Dwivedi SL, Hoisington DA, Varshney RK. Genetic relationships among seven sections of genus Arachis studied by using SSR markers. BMC Plant Biol. 2010;10:15.

67. Varshney RK, Mahendar T, Aruna R, Nigam SN, Neelima K, Vadez V, Hoisington DA. High level of natural variation in a groundnut (Arachis hypogaea L.) germplasm collection assayed by selected informative SSR markers. Plant Breeding. 2009;128:486-94.

68. Yin DM, Ji CM, Ma XL, Li H, Zhang WK, Li S, Liu FY, Zhao KK, Li FP, Li K. Genome of an allotetraploid wild peanut Arachis monticola: a de novo assembly. GigaScience. 2018;7:giy066.

69. Grabiele M, Chalup L, Robledo G, Seijo G. Genetic and geographic origin of domesticated peanut as evidenced by $5 \mathrm{~S}$ rDNA and chloroplast DNA sequences. Plant Syst Evol. 2012;298:1151-65. 
70. Seijo JG, Lavia Gl, Fernandez A, Krapovickas A, Ducasse D, Moscone EA. Physical mapping of the $5 S$ and 18S-25S rRNA genes by fish as evidence that Arachis duranensis and A. ipaënsis are the wild diploid progenitors of A. hypogaea (Leguminosae). Am J Bot. 2004;91:1294-303.

71. Kochert G, Stalker HT, Gimenes M, Galgaro L, Lopes CR, Moore K. RFLP and cytogenetic evidence on the origin and evolution of allotetraploid domesticated peanut, Arachis hypogaea (Leguminosae). Am J Bot. 1996; 83:1282-91.

72. Seijo G, Lavia Gl, Fernandez A, Krapovickas A, Ducasse DA, Bertioli DJ, Moscone EA. Genomic relationships between the cultivated peanut (Arachis hypogaea, Leguminosae) and its close relatives revealed by double GISH. Am J Bot. 2007;94:1963-71

73. Du FK, Petit RJ, Liu JQ. More introgression with less gene flow: chloroplast vs. mitochondrial DNA in the Picea asperata complex in China, and comparison with other conifers. Mol Ecol. 2009;18:1396-407.

74. Moore MJ, Soltis PS, Bell CD, Burleigh JG, Soltis DE. Phylogenetic analysis of 83 plastid genes further resolves the early diversification of eudicots. Proc Natl Acad Sci U S A. 2010;107:4623-8.

75. Patel RK, Jain M. NGS QC toolkit: a toolkit for quality control of next generation sequencing data. PLoS One. 2012;7:e30619.

76. GenBank. https://www.ncbi.nlm.nih.gov/genbank.

77. Langmead B, Trapnell C, Pop M, Salzberg SL. Ultrafast and memory-efficient alignment of short DNA sequences to the human genome. Genome Biol. 2009;10:R25

78. Bankevich A, Nurk S, Antipov D, Gurevich AA, Dvorkin M, Kulikov AS, Lesin VM, Nikolenko SI, Pham S, Prjibelski AD. SPAdes: a new genome assembly algorithm and its applications to single-cell sequencing. J Comput Biol. 2012;19:455-77.

79. Dierckxsens N, Mardulyn P, Smits G. NOVOPlasty: de novo assembly of organelle genomes from whole genome data. Nucleic Acids Res. 2016; 45:e18.

80. Wyman SK, Jansen RK, Boore JL. Automatic annotation of organellar genomes with DOGMA. Bioinformatics. 2004;20:3252-5.

81. Lohse M, Drechsel O, Bock R. OrganellarGenomeDRAW (OGDRAW): a tool for the easy generation of high-quality custom graphical maps of plastid and mitochondrial genomes. Curr Genet. 2007;52:267-74.

82. Sequin--a DNA sequence submission tool. https://www.ncbi.nlm.nih.gov/ projects/Sequin

83. McKenna A, Hanna M, Banks E, Sivachenko A, Cibulskis K, Kernytsky A, Garimella K, Altshuler D, Gabriel S, Daly M. The genome analysis toolkit: a MapReduce framework for analyzing next-generation DNA sequencing data. Genome Res. 2010;20:1297-303.

84. Frazer KA, Pachter L, Poliakov A, Rubin EM, Dubchak I. VISTA: computational tools for comparative genomics. Nucleic Acids Res. 2004;32:W273-W9.

85. Krzywinski MI, Schein JE, Birol I, Connors J, Gascoyne R, Horsman D, Jones SJ, Marra MA. Circos: an information aesthetic for comparative genomics. Genome Res. 2009:19:1639-45.

86. Thiel T, Michalek W, Varshney RK, Graner A. Exploiting EST databases for the development and characterization of gene-derived SSR-markers in barley (Hordeum vulgare L.). Theor Appl Genet. 2003;106:411-22.

87. Lavin M, Pennington RT, Klitgaard BB, Sprent Jl, de Lima HC, Gasson PE. The dalbergioid legumes (Fabaceae): delimitation of a pantropical monophyletic clade. Am J Bot. 2001;88:503-33.

88. Bi GQ, Mao YX, Xing QK, Cao M. HomBlocks: a multiple-alignment construction pipeline for organelle phylogenomics based on locally collinear block searching. Genomics. 2018;110:18-22.

89. Darling AC, Mau B, Blattner FR, Perna NT. Mauve: multiple alignment of conserved genomic sequence with rearrangements. Genome Res. 2004;14: 1394-403.

90. Castresana J. Selection of conserved blocks from multiple alignments for their use in phylogenetic analysis. Mol Biol Evol. 2000;17:540-52.

91. Nguyen L-T, Schmidt HA, von Haeseler A, Minh BQ. IQ-TREE: a fast and effective stochastic algorithm for estimating maximum-likelihood phylogenies. Mol Biol Evol. 2014;32:268-74.

92. Ronquist F, Huelsenbeck JP. MrBayes 3: Bayesian phylogenetic inference under mixed models. Bioinformatics. 2003;19:1572-4.

93. Wolfe KH, Li W-H, Sharp PM. Rates of nucleotide substitution vary greatly among plant mitochondrial, chloroplast, and nuclear DNAs. Proc Natl Acad Sci U S A. 1987;84:9054-8.

94. Simmons MP, Ochoterena H. Gaps as characters in sequence-based phylogenetic analyses. Syst Biol. 2000;49:369-81.
95. Müller K. SeqState: primer design and sequence statistics for phylogenetic DNA datasets. Appl Bioinform. 2005:4:65-9.

96. Drummond AJ, Rambaut A. BEAST: Bayesian evolutionary analysis by sampling trees. BMC Evol Biol. 2007;7:214

97. Saslis-Lagoudakis C, Chase MW, Robinson DN, Russell SJ, Klitgaard BB. Phylogenetics of neotropical Platymiscium (Leguminosae: Dalbergieae): systematics, divergence times, and biogeography inferred from nuclear ribosomal and plastid DNA sequence data. Am J Bot. 2008;95:1270-86.

\section{Publisher's Note}

Springer Nature remains neutral with regard to jurisdictional claims in published maps and institutional affiliations.
Ready to submit your research? Choose BMC and benefit from:

- fast, convenient online submission

- thorough peer review by experienced researchers in your field

- rapid publication on acceptance

- support for research data, including large and complex data types

- gold Open Access which fosters wider collaboration and increased citations

- maximum visibility for your research: over $100 \mathrm{M}$ website views per year

At $\mathrm{BMC}$, research is always in progress.

Learn more biomedcentral.com/submissions 